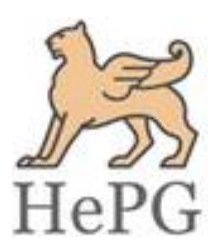

ISSN: 2348-1900

Plant Science Today

http://www.plantsciencetoday.online

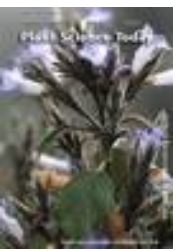

OPEN (-) ACCESS

Opinion

\title{
Do Fabaceae species with physical dormancy occur mostly in the temperate ecosystems? A rebuttal to using global biodiversity information facility (GBIF) analysis
}

\author{
Ganesh K. Jaganathan \\ University of Shanghai for Science and Technology, 516 Jungong Road, Shanghai 200 093, P.R. China
}

\section{Article history}

Received: 26 October 2019

Accepted: 15 December 2019

Published: 04 February 2020

\section{Publisher}

Horizon e-Publishing Group

\section{*Correspondence}

Ganesh K. Jaganathan

$\square$ jganeshcbe@gmail.com

\begin{abstract}
Physical dormancy (PY) is a phenomenon wherein seed coats are impermeable to water. This feature prevents immediate germination in seeds, therefore considered as an adaptive trait in species of Mediterranean and tropical ecosystem, where rainy season is the most favorable time for germination. However, using dataset available for Fabaceae collected from global biodiversity information facility (GBIF), the largest family with PY, recent studies have provided evidence contrasting this assertion. This viewpoint has arisen owing to the fact that the data were gleaned by georeferencing the Fabaceae species distribution from GBIF, which is under-represented for the tropical vegetation. This is similar to other reports available in other plant and animal distribution models, where GBIF data is not an accurate representation of distribution. A closer inspection of the data available in literature suggests that using GBIF database alone to map the distribution of Fabaceae species represents the extreme end of biased data causing misperception and could mislead the scientific community, particularly ecologists, conservationists and/or policy makers.
\end{abstract}

Keywords: Fabaceae; tropics; impermeable seed coat; GBIF; ecological adaptation

Citation: Jaganathan G K. Do Fabaceae species with physical dormancy occur mostly in the temperate ecosystems? A rebuttal to using global biodiversity information facility (GBIF) analysis. Plant Science Today 2020;7(1):109-111. https://doi.org/10.14719/pst.2020.7.1.646

Copyright: (c) Jaganathan (2020). This is an open-access article distributed under the terms of the Creative Commons Attribution License, which permits unrestricted use, distribution, and reproduction in any medium, provided the original author and source are credited (https://creativecommons.org/licenses/by/4.0/).

Indexing: Plant Science Today is covered by Scopus, Web of Science, BIOSIS Previews, ESCI, CAS, AGRIS, UGC-CARE, CABI, Google Scholar, etc. Full list at http://www.plantsciencetoday.online
Impermeable seed coats, ie. physical dormant (PY) occurring only in some genera of 19 angiosperm families-yet dominating the global flora by representing c. $25 \%$ of the known plants offers ecological fitness for the species regeneration in dry and seasonal ecosystems $(1,2)$. Consequently, PY species are known to be predominantly distributed in Mediterranean and tropical vegetation, where seasonality is high $(2,3)$. This assumption is exceptionally supported by the fact that onset of impermeability coincides with drop in seed moisture content to species-specific levels (4). Thus, the higher temperature and lower humidity in the tropics, dry the seeds to lower moisture content resulting in the development of impermeability and lower temperature along with an increase in 
humidity. Therefore, poleward movement decreases the incidence of PY (1). However, two recent publications $(5,6)$ have provided contrary evidence to this trend based on the data available on Fabaceae. Indeed, Fabaceae is one of the largest plant families in terms of number of species with PY, and being third largest flowering plant family distributed in diverse climates and ecosystem. Yet, it has been strongly stated that very few, if any, Fabaceae species occurring in the tropics have PY and rather most of the Fabaceae species occurring in the tropics have non-dormant seeds (5). They went further and articulated that PY is more prevalent in temperate ecosystems. Here, contending this view, it is argued that Fabaceae species with PY do occur in the tropics and presumably more than in temperate zone.

In a survey, 100 species of Fabaceae occurring in the tropical vegetation of Sri Lanka it was observed that 86 of them had PY, 9, 2 and 3 had non-dormant, physiological dormancy (PD) and physiological epicotyl dormancy respectively (7). In an ongoing work of 50 other Fabaceae species in Western Ghats of India with tropical climate that were not listed (7), it was found that 45 of them have PY; 2 species with non-dormant seeds; 2 of them with PD and 1 species having combinational dormancy, wherein seed coats are impermeable to water and the embryo also has PD, ie. combinational dormancy (PY+PD). Yet, a dataset of 813 Fabaceae species revealed that PY is rare in the tropics (5). Even if one assumes only 131 species, 45 of our unpublished results have PY in the tropics, this accounts for considerable proportion of the PY species of Fabaceae occurring in the tropics (7). Furthermore, there are numerous authors who have reported the existence of PY in Fabaceae colonizing in the tropics (8-10). Besides, reanalysis of data presented by consulting the original references cited for 692 PY species (1), for which location can be unambiguously assigned as tropics or temperate [note: 1291 dormant species were included in another study (6)] revealed that the $72 \%$ comes from tropical zone. Thus, the claim that PY occurs less frequently in species of Fabaceae colonizing the tropics is equivocal.

A more common argument proposed by several seed researchers on this subject matter is evidence for occurrence does not equate to species abundance. However, personal communication with several researchers within tropical ecosystems including Australia, India, Sri Lanka, Brazil, African countries, Malaysia, Indonesia, Nepal, Thailand, Argentina suggest that Fabaceae species with PY are abundant and in some cases dominate. The evidence for adaptive role of PY in the seeds of plants growing in the tropics is overwhelming and the ecological benefits of species with an impermeable seed coat within the tropical ecosystem have been discussed comprehensively before $(1,2,11)$, therefore does not warrant further emphasizing. In short, PY seeds offers a stable strategy for seeds to persist in the soil until favourable time and also spread the risk of germination over years (1). Despite these vast literature, the question is why did Wyse and Dickie (5) find fewer species with PY in Fabaceae occurring in the tropics? The answer to this lies in the use of global biodiversity information facility (GBIF) data to map the distribution of species in Fabaceae. GBIF data suffer from extreme bias both in sampling design and recording intensity with reference to the gridding used (12). Such problems with GBIF data on species distribution models have been acknowledged by the scientific community and the reports by GBIF working group (13) explicitly agree that one of the major problems with georeferencing function is the lack of accuracy. For example, in an attempt to compare the distribution ranges of Lepidoptera insects (family Sphingidae) available in GBIF and complied distributional data from literature, it was found that GBIF data provided more records but less information on range filling, range extent and climatic niches of species (14). To date, GBIF is the largest online portal that accumulates digitized information of species distribution, yet all distributional databases are spatially biased due to nation-wide differences in funding and data sharing policies (15). To this end, suggestions were made to use GBIF only as a reference for understanding species distribution and this type of studies require further analysis with literature compilation or using other distribution mapping facilities (16). Whilst careful curation of data might be applied to species modelling, distribution of species at local or even continental scales when combined with other techniques (17), caution was expressed on using GBIF data per se on remarking species distribution at a global scale (16). Given that GBIF has much better coverage in Europe and United States of America (both within the temperate zone), the species in the tropical ecosystems are under-represented (18), which resulted in misinterpretation on Fabaceae distribution reported by the two studies $(5,6)$. Several species from tropics are not included in GBIF, thus creating a bias (7). Consequently, the analysis for Fabaceae distribution by georeferencing the data available on GBIF represents another case of biased data causing misperception and could mislead the scientific community and/or policy makers.

\section{Competing interest statement}

The author declares no conflict of interest.

\section{Acknowledgement}

Financial support by National Science Foundation of China (NSFC) with grant number 31750110474 is gratefully acknowledged for the studies on physically dormant species. 


\section{References}

1. Baskin CC, Baskin JM. Seeds: Ecology, Biogeography and Evolution of Dormancy and Germination. Second ed. San Diego, USA: Elsevier; 2014.

2. Khurana E, Singh J. Ecology of tree seed and seedlings: implications for tropical forest conservation and restoration. Current Science 2001;80(6):748-57.

3. Jaganathan GK, Song D, Liu B. Diversity and distribution of physical dormant species in relation to ecosystem and life-forms. Plant Science Today 2017;4(2):55-63. https://doi.org/10.14719/pst.2017.4.2.293

4. Jaganathan GK. Influence of maternal environment in developing different levels of physical dormancy and its ecological significance. Plant Ecology 2016;217(1):71-79. https://doi.org/10.1007/s11258-015-0560-y

5. Wyse SV, Dickie JB. Ecological correlates of seed dormancy differ among dormancy types: a case study in the legumes. New Phytologist 2018;217(2):477-79. https:// doi.org/10.1111/nph.14777

6. de Casas RR, Willis CG, Pearse WD, Baskin CC, Baskin JM, Cavender-Bares J. Global biogeography of seed dormancy is determined by seasonality and seed size: a case study in the legumes. New Phytologist 2017;214(4):1527-36. https://doi.org/10.1111/nph.14498

7. Jayasuriya KG, Wijetunga AS, Baskin JM, Baskin CC. Seed dormancy and storage behaviour in tropical Fabaceae: a study of 100 species from Sri Lanka. Seed Science Research 2013;23(4):257-69. https://doi.org/10.1017/S0960258513000214

8. Daibes LF, Pausas JG, Bonani N, Nunes J, Silveira FA, Fidelis A. Fire and legume germination in a tropical savanna: ecological and historical factors. Annals of Botany https://doi.org/10.1093/aob/mcz028 2019;123(7):1219-29.

9. Burrows GE, Alden R, Robinson WA. The lens in focuslens structure in seeds of 51 Australian Acacia species and its implications for imbibition and germination. Australian Journal of Botany 2018;66(5):398-413. https://doi.org/10.1071/BT17239

10. Escobar DF, Silveira FA, Morellato LPC. Timing of seed dispersal and seed dormancy in Brazilian savanna: two solutions to face seasonality. Annals of Botany
2018;121(6):1197-209.

https://doi.org/10.1093/aob/mcy006

11. Jaganathan GK. Crypsis hypothesis as an explanation for evolution of impermeable coats in seeds is anecdotal. Ecological Research 2018;33(5):857-61. https://doi.org/10.1007/s11284-018-1590-4

12. Yesson C, Brewer PW, Sutton T, Caithness N, Pahwa JS, Burgess $\mathrm{M}$, et al. How global is the global biodiversity information facility? PloS One 2007;2(11):e1124. https:// doi.org/10.1371/journal.pone.0001124

13. Anderson RP, Araújo M, Guisan A, Lobo JM, MartínezMeyer E, Peterson AT, et al. Are species occurrence data in global online repositories fit for modeling species distributions ? The case of the Global Biodiversity Information Facility (GBIF). Final Report of the Task Group on GBIF Data Fitness for Use in Distribution Modelling. Global Biodiversity Information Facility (GBIF), 2016.

14. Beck J, Ballesteros-Mejia L, Nagel P, Kitching IJ. Online solutions and the 'W allacean shortfall': what does GBIF contribute to our knowledge of species' ranges? Diversity and Distributions 2013;19(8):1043-50. https://doi.org/10.1111/ddi.12083

15. Beck J, Böller M, Erhardt A, Schwanghart W. Spatial bias in the GBIF database and its effect on modeling species' geographic distributions. Ecological Informatics 2014;19:10-15. https://doi.org/10.1016/j.ecoinf.2013.11.002

16. Duputié A, Zimmermann NE, Chuine I. Where are the wild things? Why we need better data on species distribution. Global Ecology and Biogeography 2014;23(4):457-67. https://doi.org/10.1111/geb.12118

17. Randin CF, Paulsen J, Vitasse Y, Kollas C, Wohlgemuth T, Zimmermann NE, et al. Do the elevational limits of deciduous tree species match their thermal latitudinal limits? Global Ecology and Biogeography 2013;22(8):91323. https://doi.org/10.1111/geb.12040

18. Feeley KJ, Silman MR. The data void in modeling current and future distributions of tropical species. Global Change Biology 2011;17(1):626-30. https://doi.org/10.1111/j.1365-2486.2010.02239.x 